\title{
A PESTE E OS PRECEITOS DIETÉTICOS NO REGIMENTO DE PRESERVAÇÃO DA PESTILÊNCIA (LÉRIDA, 1348)
}

\section{The plague and the dietetic precepts on Regimen of Protection Against Pestilence (Lérida, 1348)}

\author{
Profa. Dra. Maria Dailza da Conceição Fagundes \\ Docente do Programa de Pós-Graduação em Estudos Culturais, Memória e Patrimônio \\ Docente de História Medieval na \\ Universidade Estadual de Goiás - Campus Cora Coralina \\ ORCID: https://orcid.org/0000-0001-9974-041X \\ E-mail: dailzafagundes@gmail.com
}

Recebido em: 29/09/2020

Aprovado em: 10/12/2020

Resumo: No século XIV, no contexto da peste, físicos que exerciam o ofício de mestres nas universidades criaram um novo gênero da literatura médica medieval: os Regimentos de Epidemia. Nesses escritos, predominam preceitos com o desígnio de informar a população de determinada localidade sobre como proteger-se dessa enfermidade. O Regimento de preservação da pestilência, um dos primeiros tratados pertencentes a esse gênero, foi composto em 1348, por Jacme d'Agramont, físico e mestre na Faculdade de Medicina da Universidade Lérida. Nessa obra, embasando-se nas teorias médicas de auctoritates antigas e árabes, o autor explica o surgimento de epidemias a partir da mudança ou alteração na qualidade e substância do ar que se tornava corrompido. O propósito da obra, escrita em catalão e tendo como destinatários a elite urbana de Lérida, era fornecer aos moradores da cidade, orientações práticas e de cunho dietético acerca da pestilência. Nesta perspectiva, a proposta deste trabalho é compreender, na fonte em análise, a concepção de peste, a relação entre $\mathrm{o}$ ar e o surgimento de doenças pestilentas e as principais medidas preventivas prescritas por Jacme d'Agramont.

Palavras-chave: Peste. Regimento de epidemia. Jacme d'Agramont.

Abstract: On the $14^{\text {th }}$ century, in the context of the plague, physicians who exercised the craft of masters on the universities created a new medieval medical literature genre: The Epidemic Regimen. On these writings, there is a prevalence of precepts that seeks to inform the population of a particular region on how to protect themselves from this infirmity. The Regimen of Protection Against Pestilence, one of the first treaties to belong to this genre, composed in 1348, by Jacme d'Agramont, physician and master on the Medicine Faculty from the University of Lleida. On this work, supporting himself on the medical theories of ancient and Arabian auctoritates, the author explains the emergence of the epidemics from the change or alteration on the quality and substance of the air which became corrupted. The purpose of the work, written in Catalan and meant for the urban elite from Lleida, was to provide the city dwellers, practical guidelines of dietetic nature regarding the pestilence. On this perspective, the proposal of this work is to comprehend, on the analyzed source, the plague conception, the relation between the air and the emergence of pestilent diseases and the main preventive measures prescribed by Jacme d'Agramont.

Keywords: Plague. Epidemic Regimen. Jacme d'Agramont. 


\section{Introdução}

Nos escritos médicos, compostos no contexto da peste no século XIV, essa enfermidade, descrita como pesti, epidemia, pestilência e mortalidade, foi objeto de preocupação e estudo pelos físicos e mestres das universidades. Neste período, esses intelectuais sintetizarem os saberes das matrizes antigas e árabes em preceitos práticos direcionados aos habitantes das cidades com o objetivo de prevenir a epidemia. Para esse artigo ${ }^{1}$, selecionamos o Regiment de preservació de pestilència (Regimento de Preservação da Pestilência), considerada a primeira obra pertencente ao novo gênero da literatura médica que tinham como foco essa doença. A sua análise centrará principalmente nos preceitos preventivos acerca da peste e também nas concepções acerca da relação entre o ar e o meio ambiente e o surgimento de doenças epidêmicas.

Em relação ao gênero médico literário, os Regimentos de Epidemia são escritos em que predominam preceitos com o desígnio de informar como prevenir-se contra a peste. Nesse sentido, diferentemente dos Regimentos de saúde, composto por conselhos dietéticos prescritos a partir da compleição individual do paciente, os regimentos de epidemia eram dirigidos à coletividade e escritos quando uma enfermidade afetava toda a população.

Esse novo gênero da literatura médica surgiu no século XIV, no contexto da peste. Assim, dentre os vários exemplos de obras médicas pertencentes a essa tipologia, temos: o Regimento de preservação da pestilencia, de abril de 1348, em Lérida, pelo físico catalão Jacme d'Agramont; o Compendium de epidemia, uma obra coletiva escrita em outubro de 1348, por doutores da faculdade de medicina da Universidade de Paris; a Epistola e regimento de epidemia, composto entre 1348 e 1349 por Alfonso de Córdoba, em Montpellier (ARRIZABALAGA, 1994:239-240).

O Regimen em estudo foi escrito, em catalão, na cidade de Lérida pelo físico Jacme d'Agramont (? - 1348). No prólogo, o autor nos fornece alguns dados sobre a sua naturalidade e, ao finalizar a obra, apresenta informações sobre o seu ofício e espaço de atuação quando afirma que: "Este tratado foi concluído no ano de Nosso Senhor Jesus Cristo 1348, na Vigília de São Marcos [24 de abril], por Jacme d'Agramont, mestre em Artes e Medicina" (RPP², art. VI, cap. I). 
Quanto à estrutura, o Regimento de preservação da pestilência contém um prólogo, uma introdução e seis artigos. No prólogo, o autor apresenta o objetivo da composição da obra; na introdução, indica as propriedades do ar temperado em suas qualidades e substâncias e aponta as maneiras pelas quais pode haver mudança e alteração no ar. Em relação aos artigos, no primeiro, define a pestilência. No segundo, dividido em dois capítulos, apresenta a maneira como a pestilência é gerada devido à alteração do ar em suas qualidades e sua substância; indica as coisas que causam pestilência na cidade, a uma rua, a uma casa em particular. No terceiro artigo, o foco são os sinais que indicam que a pestilência se aproxima ou já está no ar. No quarto artigo, o autor discute a alteração e mudança que o ar pestilento causa nos seres vivos. No quinto artigo, denominado pelo autor como o regimento de preservação, aborda as seis coisas não naturais do ponto de vista preventivo: contra o ar pestilento por causa do calor e do odor, exercícios, alimentos e medicamentos, o sono, purgante e sangrias, acidentes da alma. Por último, no sexto artigo, discute a peste moral ${ }^{3}$.

Em 1300, durante o reinado de Jaime II (1291 - 1327) de Aragão, foi criado em Lérida, um Studium Generale, com as faculdades de Direito, Medicina e Artes. A escolha dessa cidade aconteceu, mormente, devido à sua posição geográfica. Por um lado, ficava perto de Barcelona, cidade onde a corte instalava-se por mais tempo. Do mesmo modo, localizava-se na região central do reino, por conseguinte, seria um lugar de fácil acesso às principais cidades de Aragão. Antes, os aragoneses, normalmente, estudavam em instituições de ensino superior, como a Faculdade de Medicina em Montpellier, cidade pertencente à Aragão, mas localizada no reino francês ${ }^{4}$. Contudo, a longa distância dificultava o acesso dos jovens oriundos de Aragão. Além disso, o monarca Jaime II ansiava por ter físicos com formação universitária, próximos a Barcelona e a Valência para atenderem a família real quando fosse necessário (FAGUNDES, 2014: 39).

A relação de Jacme d'Agramont com essa cidade é ressaltada no prólogo quando ele apresenta o objetivo da composição do tratado:

Quis me esforçar em fazer o seguinte tratado porque sou natural desta cidade e, além disso, continuo recebendo honras e grandes benefícios de toda a cidade. Por isso, desejo que minha pouca ciência possa fornecer algum proveito e evitar todo o dano a Lérida e preservar a cada um de estar doente durante o tempo da pestilência. Humildemente e com a reverência devida, eu, 
mestre Jacme d'Agramont, apresento a vós, honrados senhores e conselheiros da cidade de Lérida, [este tratado] (RPP, Prólogo).

Nesta passagem, percebe-se que além de ser natural de Lérida, outra ligação de Jacme d'Agramont com o local é por ser o espaço de sua atuação enquanto físico e mestre na Universidade, localizada nessa cidade. Do mesmo modo, ao mencionar, na passagem acima, as honras e benefícios recebidos, demonstra sua relação com os conselhos municipais e a elite urbana que eram responsáveis pelos pagamentos dos mestres que atuavam nas faculdades da instituição. Observa-se ainda que o objetivo da composição da obra não é fornecer saberes médicos para os físicos, mas instruir a população da cidade sobre como manter a saúde em tempos de epidemia.

Ainda no prólogo, o autor diferencia o regimento de preservação da epidemia do regimento de cura, apresentando uma separação entre os preceitos dietéticos ${ }^{5}$ voltados para a prevenção e as indicações terapêuticas que envolvem, por exemplo, a elaboração de medicamentos. Nesta perspectiva, para Jacme d'Agramont, o regimento de cura que contém as receitas medicamentosas é campo de atuação do físico, portanto, não poderiam ser utilizadas sem o seu acompanhamento. Por outro lado, as recomendações dietéticas e de cunho preventivo que ocupam a maior parte do tratado podem ser seguidas por todos os moradores de Lérida sem auxílio médico. Assim, conforme as palavras do autor, a obra foi feita para a utilidade pública e, nesse sentido, solicita aos destinatários do Regimen, ou seja, a elite urbana, que compartilhem o tratado com toda pessoa que queira uma cópia (RPP, Prólogo).

Este texto foi estruturado em três partes. Na primeira, a proposta é discutir a relação entre o ar e o meio ambiente e o surgimento de epidemias a partir do arcabouço teórico e conceitual utilizado por Jacme d'Agramont. Em seguida, o foco é a análise das causas e sinais da peste. Por fim, as discussões centram-se em alguns preceitos preventivos indicados pelo autor, sobretudo as recomendações referentes aos cuidados com o ar e o entorno das pessoas, a alimentação e os acidentes da alma.

\section{A relação entre o ar e meio ambiente e o surgimento de doenças pestilentas}


Jacme d'Agramont, no prólogo de sua obra, ao apresentar as notícias acerca da peste em regiões vizinhas à Lérida, ressalta o temor e o medo da população em relação às enfermidades pestilentas:

A experiência demonstra que quando uma casa pega fogo, todos os vizinhos têm temor e aqueles que estão mais próximos a ela são os que mais devem ter medo. Pelo qual, como tem ouvido dizer a pessoas dignas de fé que a epidemia ou pestilência e mortalidade de pessoas reinam e tem reinado em algumas regiões vizinhas. Assim, não é estranho sentir temor e medo (RPP, Prólogo).

Como exposto acima, o autor, com base em sua experiência (practica medica), afirma que uma habitação quando pega fogo torna-se um risco de incêndio para as casas vizinhas. Do mesmo modo, as enfermidades compreendidas como pestilentas tendem a se espalhar de uma região para outra, sobretudo a partir do ar e o meio ambiente contaminado.

No Regimento de epidemia em análise, a enfermidade denominada pestilência é definida como "a mudança contra a natureza do ar em suas qualidades ou em sua substância que causa corrupção, enfermidade e morte súbita nos seres vivos de diversas regiões" (RPP, art. I, cap. I). Para o autor, são consideradas pestilentas, as doenças causadas pelas alterações nas qualidades e substâncias do ar, pois estas atingem todos os seres vivos.

Essa definição é comum no pensamento médico medieval que concebia uma estreita relação entre o ar e meio ambiente e os mecanismos que propagam as epidemias. Seguindo as matrizes antigas e árabes, o ar é concebido como um dos quatro elementos constitutivo de tudo no universo (terra, ar, água e fogo), ou seja, a primeira coisa natural. Por outro lado, ele refere-se também a primeira coisa não natural que engloba o conjunto de elementos que tem em comum o fato de formar o ambiente que rodeia o homem. Por isso os preceitos médicos referentes ao ar e ao meio ambiente envolvem os ventos, o clima, a geografia física, as vestimentas e as habitações.

Assim, Jacme d'Agramont ao definir a peste como a mudança contra natura do ar, aborda essa enfermidade como um problema médico e utiliza um arcabouço teórico fornecido pelo galenismo árabe medieval. Por essa perspectiva, compreendia a doença a partir do conjunto de teorias e doutrinas inspiradas nos escritos galênicos que foram 
estruturadas pelos médicos árabes e sintetizadas, sobretudo, nas teorias das coisas naturais (res naturales), não naturais (res non naturales) e contra a natureza (res contra natura). Tendo o conhecimento acerca dessas teorias, os físicos medievais compreendiam a saúde e também as ferramentas para preservá-la.

As coisas naturais referem-se a algo interno ao corpo humano. Assim, esse conceito relaciona-se à fisiologia, ou seja, trata das funções orgânicas e dos processos vitais do corpo. Essa teoria engloba os quatro elementos que constituem o universo (terra, água, ar e fogo); as compleições; os humores (sangue, bílis amarela, bílis negra e fleuma); as partes sólidas do corpo (cérebro, coração, fígado,...); as operações (funções desempenhadas em cada parte sólida do corpo); e as faculdades que contribuíam para a realização das funções biológicas (formação, crescimento, locomoção, nutrição).

A compleição (em latim, complexio; em grego, krasis), segunda coisa natural, envolve a constituição física, a disposição do espírito e os temperamentos dos indivíduos. É composta pelos quatro elementos constituintes do universo (terra, água, ar e fogo), pelos humores (sangue, bílis amarela, bílis negra e fleuma) e pela mistura das qualidades (quente, seca, fria e úmida) (SANTOS e FAGUNDES, 2010: $337)$.

No Regimento de Preservação da Pestilência, Jacme d'Agramont ressalta a diversidade de compleições relacionadas ao predomínio de um dos quatro humores no corpo humano. Há também aqueles que possuem uma compleição marcada pelo equilíbrio humoral e outros cuja constituição é caracterizada pela desproporção dos humores:

alguns se alegram em ouvir músicas e instrumentos, como aqueles com compleição temperada. Existem outros com compleição corrompida e desproporcional que estão doentes, pois lamentam escutar melodias e quando estavam com saúde sentia prazer em ouvir canções. Ainda observamos que alguns gostam de comer ou beber coisas doces, como os Fleumáticos. Outros se alegram em comer e beber coisas azedas, como os coléricos. Alguns estão felizes e sorrindo o dia todo, como os sanguíneos. E outros estão sempre tristes de modo que em nenhum momento eles riem de coração, e estes são melancólicos. Mesmo alguns são ousados e briguentos, como os coléricos; outros são temerosos e calmos, como os fleumáticos e melancólicos (RPP, Introdução, cap. II, grifos nossos). 
Nessa perspectiva, observando o predomínio das qualidades no corpo, Jacme d'Agramont classifica as compleições em seis tipos: colérico (quente e seca como o sangue), fleumático (fria e úmida como a fleuma), melancólico (seco e frio como a bile negra), sanguíneo (quente e úmido como o sangue), temperada quando se tem o equilíbrio dos humores e corrompida ou desproporcional quando há o excesso de um dos humores no corpo.

Por coisas não naturais compreende-se como algo exterior à natureza do corpo humano, no entanto, essencial para o seu funcionamento: o ar e o meio ambiente; os alimentos e as bebidas; o exercício e o repouso; a retenção e a expulsão; o sono e a vigília e as paixões da alma. Normalmente, os regimentos de saúde são estruturados em torno desses seis elementos. Já em regimentos de epidemia como o de Jacme d'Agramont, o foco principal dos preceitos é a peste que é abordada a partir de alguns temas que passam a ser comuns nesse gênero da literatura médica: ao mesmo tempo em que o autor apresenta a definição, as causas e sinais da pestilência, indica também as medidas preventivas e terapêuticas. As coisas não naturais são tratadas nas passagens referentes ao ar e ao meio ambiente e também nas prescrições acerca das indicações dietéticas ou de preservação.

Já as coisas contra a natureza (contra natura), são as enfermidades que, no galenismo medieval, são consideradas um desequilíbrio dos humores. Tendo como embasamento os preceitos das matrizes antigas e árabes, os físicos recorriam à teoria humoral para explicar o estado de saúde e doença. De acordo com essa teoria, o corpo humano é constituído por humores, a terceira coisa natural: o sangue, a fleuma, a bile amarela e a bile negra. As quatro qualidades (quente, seco, frio e úmido) dos elementos da natureza também são atribuídos aos humores do corpo e às estações do ano. Assim, o sangue era considerado quente e úmido, como o ar e a primavera; a fleuma, fria e úmida como a água e o inverno; a bile amarela, quente e seca como o fogo e o verão; a bile negra, fria e seca como a terra e o outono. Assim, a saúde e a doença manifestavam-se dependendo do estado de equilíbrio e desequilíbrio dos humores que compõem o corpo.

Assim, os físicos com base nas teorias do galenismo árabe medieval, propunham regular a vida humana a partir da perspectiva médica. Nesse sentido, a saúde era considerada como estado de equilíbrio humoral entre o corpo humano e o ambiente em seu entorno. Portanto, era necessário observar as coisas não naturais 
como o ar e o meio ambiente porque por um lado, dependendo da estação do ano, poderia gerar o aumento de um dos humores e, por outro, estava relacionada com o surgimento de doenças pestilentas (GARCIA-BALLESTER, 2004: 543).

A palavra ar é compreendida por Jacme d'Agramont não apenas como o elemento simples ligado à respiração, mas também como a atmosfera que nos cerca. Assim, os físicos que consideram o ar como a primeira coisa natural e não natural seguem a tradição hipocrática. No Livro II de sua obra Perì diaítes (Sobre a Dieta), Hipócrates discute centralmente a constituição dos lugares e ventos e a influência da geografia física sobre o homem. Expunha ainda a importância de distinguir os ventos de acordo com a natureza, pois em sua concepção, eles detêm a capacidade natural de umidificar e esfriar os corpos. Mas, dependendo da região e do lugar onde se originam, alguns ventos são diferentes de outros: mais quentes, secos, frios, úmidos. Assim, dependendo da constituição do paciente, um vento pode ajudar na manutenção da saúde, enquanto outros podem prejudicá-la (SOBRE A DIETA, Livro II, cap. 37-38).

Além das auctoritates antigas, Jacmes d'Agramont apoia-se igualmente nos escritos médicos árabes, sobretudo de Avicena (980 - 1037), Razis (865 - 926) e Averróis (1126-1198). Avicena, em sua obra Canon da Medicina, apresenta concepções de dietética e terapêutica que tiveram grande ascendência sobre a produção médica latina na Idade Média. Neste escrito, para discutir elementos da dietética considera-se os diversos fatores como a idade do indivíduo (infância, idade adulta, velhice), as estações do ano e as situações particulares, como as viagens. No Livro I, fornece sua definição para o ar enquanto primeira coisa natural e não natural: "Ar é um elemento que está em nosso corpo e em nossa respiração [...] Pela palavra ar compreende-se [...] a atmosfera que nos cerca" (CANON DA MEDICINA, Livro I, parte II, II, 234; IX, 309).

No século XII, o médico árabe Averróis, em sua obra Livro sobre as generalidades da medicina, conhecido no Ocidente Latino como Coliget, apresenta no livro VI, preceitos sobre como preservar os corpos de enfermidades provocadas pelo ar. Para Averróis, a explicação acerca da origem de enfermidades causadas pela alteração no ar está relacionada tanto às qualidades da primeira coisa não natural quanto à compleição do paciente. Nesse sentido, afirma que:

Quando o ar se afasta de sua natureza em qualidade ou difere no que afeta toda a sua essência e por isso se corrompe, predispõe os corpos às 
enfermidades devidas a tal complexão [...] Quando o ar se afasta de uma de suas características deve-se empregar o regimento do contrário. Por exemplo, contra o excesso de calor e secura, se emprega um regimento consistente em tomar alimentos frios e úmidos, permanecer em lugares situados ao norte que sejam equilibrados enquanto o ar, as águas e os odores (COLIGET, Livro VI, cap. XII).

A partir do exposto acima, infere-se que os preceitos recomendados têm como objetivo impedir as causas que provocam a corrução. Em geral, os físicos compreendiam a alteração do ar como um aviso de surgimento de enfermidades. Nesta situação, era recomendada como proteção a utilização de regimento dos contrários à natureza dessas doenças. Se afastar, por exemplo, dos lugares quentes com ar corrompido e estagnado e ir para lugares em que o ar fosse limpo, puro e está em movimento.

E, nesse sentido, o médico árabe recomenda a teoria do uso dos contrários. Tratase da teoria farmacológica em que as qualidades (quente, fria, seca e úmida) predominantes nos alimentos, nos medicamentos, na compleição do paciente e nas estações do ano se repelem entre si. Assim, recomenda-se ao paciente em que predominam o temperamento colérico com qualidades quentes e secas deve-se evitar todos os alimentos detentores dessas qualidades e consumir aqueles com qualidades opostas, ou seja, frios e úmidos.

Portanto, na perspectiva médica medieval, o ar e o meio ambiente eram considerados um dos elementos mais importantes para a conservação da saúde. Alguns fatores, como fumaça ou substâncias nocivas, contudo, poderiam alterar a sua qualidade, tornando-os prejudiciais. Tais modificações influenciavam o coração e, consequentemente, todo o corpo, podendo gerar, inclusive, doenças pestilentas.

Assim, a importância atribuída ao ar é por sua relação com o coração, fonte da vida, e com o pneuma, responsáveis pelo funcionamento do corpo. A primeira coisa não natural associa-se ao calor inato, situado no coração, considerado um motor responsável pelos vários fenômenos indispensáveis à vida. Era o princípio vital do homem, considerado uma chama que não pode queimar se não existe ar, de sorte que esse elemento é o que impede a extinção do calor natural. O ar inspirado entrava no coração, resfriava-o e evitava que sua humidade enfraquecesse. Assim, toda a modificação da 
qualidade desse elemento influenciava diretamente o coração e, consequentemente, o organismo inteiro (SOTRES, 1995: 267).

$\mathrm{Na}$ doutrina galênica, o pneuma era considerado um princípio vivificador que entrava aos pulmões com o ar e ia para o coração onde se misturava com o sangue. Por isso, nos escritos médicos as causas e mecanismos de produção de epidemias são encontradas no ar que se corrompe pela existência de um ambiente alterado devido a um ar estagnado, a um intenso calor ou a chuvas excessivamente prolongadas. Ao respirar, o ar corrompido chega ao coração e gera a alteração de sua compleição ao afetar a pneuma que reside nesse órgão causando a morte do individuo porque produz o desaparecimento do calor inato.

\section{As causas e os sinais de enfermidades epidemicas}

Jacmes de Agramont, na introdução do Regimen, apresenta a etimologia da palavra pestilência que é interpretada como "o tempo da tempestade que vem da claridade, ou seja, das estrelas" (RPP, art. I, cap. II). Observa-se que o físico catalão aborda a questão da influência dos astros no surgimento de enfermidades pestilentas surgidas devido à mudança na substância do ar. Partindo dessa premissa e utilizando os saberes fornecidos pelo teólogo e filósofo Alberto Magno (1200-1280), afirma que a pestilência e morte nos reinos podem ser causadas pela conjunção dos planetas Júpiter e Saturno, pois os mesmos possuem qualidades contrárias e quando se unem acabam alterando a substância do ar e consequentemente provocando o surgimento da doença Ainda discutindo as alterações ou movimentações dos astros, o autor afirma que às vezes elas podem ser visualizadas. Com base nesses preceitos, cita o caso de várias pessoas da cidade de Lérida que relataram terem visto no céu, em fevereiro de 1345, perto do amanhecer um fecho de luz incandescente, que brilhava mais que um relâmpago (RPP, art. II, parte I, cap. II; art. III, cap. I; ARRIZABALAGA, 1994: 254).

A constante influência exercida pelo macrocosmo sobre o microcosmo era considerada na medicina medieval como uma das causas das epidemias. A condição universal do ar definida como peste implicava uma mudança contra a natureza na substância deste elemento primário, ou seja, sua corrupção. Dado que o ar era considerado como o elemento vital mais básico, considerava-se que os efeitos desta suposta corrupção atingiam muitas pessoas. 
Portanto, uma das explicações para a origem da peste refere-se a diversos fatores celestes como a influência dos diferentes planetas, signos zodíacos e cometas. Nesta perspectiva, a saúde e a enfermidade do homem, o microcosmo por excelência, não podia ser pensada pelos médicos medievais sem sua relação com o macrocosmo. A compreensão sobre essa relação era imprescindível para o conhecimento do homem e das operações que como ser vivo, tinha lugar no corpo. Não se tratava somente de que havia uma correspondência entre as diferentes partes do corpo humano com as diferentes partes do céu e das estrelas, senão que qualquer função fisiológica ou qualquer tratamento que, por sua própria natureza, alterava as funções corporais, estava sob a influência dos corpos celestes ${ }^{6}$. Assim, médicos Judeus, cristãos e muçulmanos, tanto no âmbito doutrinal com base no galenismo árabe medieval como na prática médica, consideravam a observação do céu e a posição do paciente de acordo com a situação geográfica (BALLESTER, 2001: 177).

Assim, nos regimentos de epidemia, é comum a discussão acerca dos fatores responsáveis pela origem de enfermidades pestilentas. Jacme d'Agramont indica as seguintes causas que podem ser classificadas em celestes ou terrestres: 1) obra de Deus que por causa dos pecados dos homens enviou pestilência e mortalidade; 2) provocada de forma direta por ações de pessoas, "homens malvados" que, com venenos diversos, corrompem a comida; 3 ) as causas astrais, ou seja, a peste pode surgir pela conjunção de planetas; 4) a epidemia pode vir por causa dos sopros de ventos quentes e úmidos, de grande umidade do ar e putrefação de corpos; 5) o consumo de trigo e outros alimentos de regiões pestilentas; 6) o contato com pessoas pestilentas.

Em relação aos fatores que explicam a propagação da peste, destaca-se o fato do autor, ao apresentar como causa, o contato com as pessoas que estão enfermas. E, ao defender a condição epidêmica da doença, o autor a compara com outras enfermidades igualmente contagiosas no período como a lepra. Assim, afirma que outra forma de contrair a peste é pelo:

contato com doente de enfermidade pestilenta, pois de um se pega ao outro como o Fogo de Santo Antônio ${ }^{7}$, e daquele a outro. [...] E se perguntam quais são as enfermidades que se pegam de um a outro, digo que são como a lepra, sarna, febre pestilenta, varíola [...]. E universalmente toda a enfermidade que se dá por pestilência do ar (RPP, art. II, parte II, cap. I). 
$\mathrm{Na}$ passagem em questão, observa-se que, na concepção do físico catalão, a pestilência é uma enfermidade que pode ser adquirida a partir do contato com outra pessoa que já está enferma. Nesses casos, requer-se principalmente a disposição no corpo daquele a quem se pega a doença, pois, "obra e efeito sempre se da em matéria predisposta. Por isso se diz vulgarmente que mal resultado tem deixar próximo ao fogo a estopa" (RPP, art. II, parte II, cap. I). Assim, o autor considera que algumas pessoas são propensas às enfermidades pestilentas, pois possuem constituição predisposta à corrupção, ou seja, têm o corpo cheio de humores corrompidos.

Outro elemento comum nos regimentos de epidemia é a indicação dos sinais no entorno físico que anunciavam a presença da peste em determinado lugar. Tratava-se de fenômenos naturais incomuns ligados ao ar, às plantas e animais e ao padrão local de enfermidades. Eram indícios que poderiam ser observados anunciando a chegada da epidemia ou indicando que ela já se encontra no local.

Assim, Jacmes d'Agramont, elenca os sinais que indicam que a peste já está presente no ar Podemos classifica-los em quatro tipos: mudanças no ar, no comportamento dos animais, nas pessoas e nas plantações: 1) o ar turvo quando parece que vai chover, mas não chove; 2) quando o ar está carregado de pó; 3) quando o ar parece ter cor amarela; 4) grande quantidade de serpentes, lagartos e outros répteis saindo das cavernas; 5) rãs em grande abundância saindo das águas; 6) pássaros abandonando os ovos nos ninhos; 7) febres pestilentas; 8) erupções na pele; 9) frutas estragadas e trigo com odor estranho (RPP, art. III, cap. II).

Em relação aos sinais que afetam diretamente o ser humano, o físico cita as febres em que o enfermo está frio por fora, mas por dentro e próximo ao coração está muito quente:

\footnotetext{
Contudo, às vezes o enfermo não sentirá grande febre e nem o médico com o tato a encontrará, e o pulso não estará muito mudado de seu natural [...] E o enfermo morre subitamente. E o físico fica surpreso por não saber o que aconteceu [...] Além disso, aqueles que têm febre pestilenta não têm calor por fora e sentem muita angústia. Por isso, não conseguem se acalmar (RPP, art. III, cap. II).
}

Na passagem em questão, o autor relaciona também o mau odor do ar e do hálito dos que padecem com esse tipo de febre como sinal da corrupção e putrefação da substância deste elemento o que era interpretado como risco ou a presença de fato da 
doença. No Regimen em análise, é citado brevemente que a presença de febres pestilentas é acompanhada por erupções e apostemas na pele, assim como antraz, varíola e outras doenças malignas.

\section{Os preceitos preventivos no Regimento de preservação da pestilência}

De forma geral, observa-se que na maioria dos escritos médicos, seguindo as matrizes antigas e árabes, o ar é considerado o principal meio de transmissão da peste. Com base nessa concepção, acreditava-se que as pessoas adoeciam porque o ambiente corrompido atuava diretamente sobre os corpos, principalmente daqueles cuja compleição encontrava-se desequilibrada. Assim, cabia aos físicos indicar um regimento de preservação abordando elementos que ajudassem o paciente a manter o estado de saúde e evitar adquirir a mortalidade. O quinto artigo do Regimen é dedicado a essa discussão apresentando preceitos preventivos relacionados às seis coisas não naturais: ao ar e ao meio ambiente, exercícios, alimentação, sono, retenção e evacuação e as paixões da alma.

Jacme d'Agramont, partindo do pressuposto de que a difusão da peste se dava por meio do ar corrompido, afirma que a pestilência muda de uma região para outra por três razões: o ar corrompido de uma região corrompe com facilidade outro ar próximo ao local e para exemplificar cita que uma maçã podre faz com que as outras próximas a ela apodreçam; o consumo de alimentos como o trigo oriundo de regiões pestilentas; os ventos que levam e mudam o ar corrompido e pestilento de uma região para a outra (RPP, art. I, cap. I).

A pestilência é descrita como a mudança ou alteração na qualidade e substância do ar que se torna putrificado. Na perspectiva médica, o ar quando é puro possui substâncias e qualidades puras e legítimas, livres de qualquer elemento nocivo. Por outro lado, é considerado corrompido pela presença de elementos nocivos que alteram a sua qualidade e corrompem a sua substância. Com base nessas premissas, Jacme d'Agramont diferencia o ar puro, ideal para viver, do impuro responsável pelas enfermidades pestilentas:

Quando o ar de alguma região ou cidade está bem temperado em sua natureza e em suas qualidades, é transparente e limpo, e puro em sua substância, tal ar possui propriedades maravilhosas, pois prolonga a nossa vida, da alegria e conserva a saúde e faz com que se aumente a inteligência [...] Mas o ar pode 
ter mudança em duas maneiras: em suas qualidades e essa mudança se chama alteração; e em sua substância que se chama putrefação (RPP, Introdução, cap. I; II).

Assim, partindo desses preceitos e seguindo os princípios da teoria dos contrários, Agramont afirma que quando o ar é pestilento pelo excesso de calor, recomenda-se estar em lugares naturalmente ou artificialmente frescos. Em relação os locais naturalmente frios do reino aragonês, cita, como exemplo, a região de serras em Aragão ou as montanhas de Prades na Catalunha. Por outro lado, para aqueles que não podem mudar a moradia e assim, eram obrigados a permanecer em locais que não possuíam as condições consideradas ideais pelos físicos, o autor indica formas de esfriar e purificar artificialmente o ar: "Molhar o chão da habitação com vinagre e água de rosas. Espalhe pelo chão, pontas de salgueiro, folhas de nogueira, ramos de murta e rosas" (RPP, art. V, parte I, cap. I).

Do mesmo modo, quando o ar é considerado pestilento devido à corrupção e putrefação de sua substância que deixam o ambiente com odores fétidos e por influência celeste, ou seja, de alguma conjunção ou planeta, como ação preventiva recomenda-se modificar o ambiente, utilizando substâncias aromáticas visando reforçar a sua resistência à corrupção. Assim, deviam queimar na habitação alecrim, murta, cipreste, zimbro e lavanda árabe, madeira de aloés, âmbar, rosas vermelhas secas, sândalo. Do mesmo modo, indica-se também:

\footnotetext{
Queimar nas habitações, alecrim ou zimbro e fazer perfume de incenso usando outros produtos de preços baixos, como timiama e ervato. E eu digo que só fazer fogo é algo que retifica muito o ar podre em sua substância. E aconselho que este regimento seja continuado porque é um dos mais importantes e os mais necessários. Continuo a dizer que é muito útil molhar o chão da habitação com água de rosas e vinagre (RPP, art. V, parte II, cap. I).
}

Apesar da maior parte das indicações preventivas serem destinadas à elite, no trecho acima e em outras passagens da obra, o autor demonstra também a preocupação em indicar ingredientes de fácil alcance. Assim, recomenda fazer incenso para modificar o ar com substâncias aromáticas que tinha um preço mais barato como a Timiama (frangula alnus) e também o ervato (Peucedanum officinale), planta encontrada no norte do reino de Aragão que as pessoas comuns poderiam ter acesso. 
Quantos aos preceitos preventivos relacionados à alimentação, os físicos preocupavam-se com a terceira coisa não natural porque a harmonia responsável pela saúde podia ser conservada ou recuperada, graças a uma atenção particular aos alimentos consumidos que também possuíam as qualidades (quente, seco, frio e úmido). Assim, em relação ao regimento acerca da alimentação que tende a preservar os corpos de enfermidades pestilentas, o autor lista os alimentos que são benéficos e também os que devem ser evitados. A explicação dos preceitos relaciona-se tanto às qualidades da terceira coisa não natural quanto à compleição do paciente. Assim, em tempos de epidemia em que o ar está corrompido, recomendam-se cuidados acerca da dieta alimentar, sobretudo adotando a moderação na comida e na bebida. Do mesmo modo, ressalta em várias passagens a importância do uso na alimentação de vinagre, agraço, romãs, suco de laranjas e limões, seguindo a noção de equilíbrio humoral.

$\mathrm{Na}$ concepção do físico árabe, em sua obra Coliget, as pessoas com compleições quentes e úmidas estavam mais suscetíveis de ter doenças corruptivas. Por isso "devem cuidar de seus estômagos, pois uma mudança do alimento no estômago pode causar alterações nos humores do corpo. Seus alimentos devem ser com qualidades frias e secas" (COLIGET, Livro VI, cap. X). Assim, seguindo a mesma linha de preceitos indicados por Averróis, Jacme d'Agramont aconselha o uso de vinagre e frutas como a laranja e o limão, pois pela perspectiva médica medieval, esses produtos detentores das qualidades frias e secas tinham a capacidade natural de alterar a compleição, impedindo a corrupção dos humores.

Ainda seguindo essa premissa, aconselha evitar alimentos úmidos que poderiam contribuir para a putrefação, estado comum em enfermidades pestilentas, tais como: frutas que não são ácidas, peixes, aves que se alimentam perto de lagoas como gansos e patos e outras carnes que são úmidas na natureza, como leitões e cordeiros.

Apesar desta parte do Regimen ter como foco os preceitos de caráter dietético referentes à alimentação, o autor indica também alguns remédios que em sua opinião auxiliariam a preservar o corpo de doenças pestilentas. $\mathrm{Na}$ farmacologia antiga e medieval, os medicamentos eram classificados em simples quando utilizava em sua composição apenas um componente que poderia ser de origem mineral, animal e principalmente vegetal. Por outro lado, eram denominados compostos quando para elaborá-los usavam vários ingredientes. A maior parte dos fármacos indicados no 
Regimen era elaborada em forma ${ }^{8}$ de decocção e indicado que fossem diluídos em água de rosa, vinagre, vinho, etc.

$\mathrm{Na}$ obra em análise, são prescritos medicamentos compostos e simples. Primeiramente, Jacme d'Agramont recomenda tomar pela manhã, três vezes na semana, uma dracma [3,4 gramas] de triaga fina. Não é apresentada no Regimen, a composição desse fármaco. No entanto, trata-se de um medicamento composto também conhecido como teriaga indicado desde a Antiguidade para o tratamento de diversas enfermidades (RPP, art. V, parte II, cap. III).

Ainda, em relação aos medicamentos compostos, é indicado um remédio chamado metridatum 9 (mithridatum/mitridato) que na concepção de Jacme d'Agramont, se for preparado de forma verdadeira e fiel: "é tão eficaz, segundo alguns renomados autores da medicina, que quem o usa todas as manhãs na quantidade de um grão, nenhum tóxico ou veneno poderá lhe prejudicar” (RPP, art. V, parte II, cap. III).

Esse fármaco, conhecido desde a Antiguidade e citado por físicos como Galeno como eficaz para prevenir pestilencia, é considerado um antídoto "universal" contra todos os tipos de venenos. A sua composição contava com mais de sessentas ingredientes, medicamentos simples, como mirra, açafrão, agárico, gengibre, canela, incenso, cardamomo, gálbano e erva de São João (VENY, 1999).

O autor apresenta somente a receita de um medicamento composto que é encontrado também em outros regimentos de epidemia ou tratados em que dedicam alguns capítulos aos preceitos sobre a peste, como na obra Medicina Sevillana, composta em 1380 pelo físico Juan de Aviñon. Jacme de Agramont ao apresentar esse medicamento afirma que é muito recomendo por autoridades árabes:

Existe ainda uma confecção muito maravilhosa e muito elogiada por Avicena, por Razis e por Averróis e por outros autores solenes da medicina que disseram que ninguém que dela tomou a quantidade de uma dracma $[3,4$ gramas], todas as manhãs, com uma onça [28, 3 gramas] de vinho bem aguado não morreria aquele ano pela pestilência do ar (RPP, Art. V, parte II, cap. III).

O medicamento acima, prescrito para tempos de epidemias causadas pela corrupção do ar é o único que o autor indica todos os componentes: uma parte de Aloé sucotrino (quente em primeiro grau ${ }^{10}$ e seco em terceiro), metade dessa parte com mirra (quente e seca em terceiro grau), açafrão (quente em segundo grau e seco em terceiro) e 
água de rosa (fria e seca em primeiro grau). Observa-se o predomínio de ingredientes de origem árabe e com as qualidades quente e seca. Ao prescrever um remédio era importante saber a intensidade da ação da substância sobre a compleição humana que poderia ser em primeiro, segundo, terceiro e quarto graus. Nessa perspectiva, ao indicar o caráter medicamentoso da mirra, por exemplo, observa-se que é quente e seca em terceiro grau, ou seja, era mais quente e seca que a compleição humana. Em geral, notase que as substâncias indicadas nas prescrições são mais secas e tão quentes quanto à compleição.

No entanto, apesar do tratado ter sido produzido em catalão, a receita é apresentada em latim. E, nesse sentido, corrobora com o que Agramont ressaltou no prólogo da obra: a confecção de medicamentos não pode ser feita sem o auxílio médico. Assim, ressalta a importância de quem desejasse fazer esse remédio procurasse o auxílio de um especieiro (especialista em drogas aromáticas e medicinais).

Do mesmo modo, indica alguns medicamentos simples de origem vegetal, como o suco de capud monachi, também denominada taraxacum, dandelion, (dente de leão) e de bruneta conhecida como Prunella vulgaris. Outra recomendação é o uso da erva escabiosa que deveria ser cozinhada em fogo lento com água de rosas (RPP, art. V, parte II, cap. III). Essa planta também conhecida como scabiosa é considerada pelo físico árabe Abu-l-Salt de Dênia (1068-1134) em seu Livro de Medicamentos Simples como detentora das qualidades quente e seca em quarto grau. Assim, no que ser refere à escabiosa, é considerada pela farmacologia medieval como extremamente mais quente e seca que a compleição humana. Portanto, indicada contra doenças corruptivas.

Além da prescrição de medicamentos, outro aspecto terapêutico indicado do ponto de vista preventivo, refere-se à quinta coisa não natural: a evacuação e a retenção. Agramont, considerando que muitos não seguiam o princípio da moderação em relação à comida e à bebida, aconselhava a purgação do corpo. Antes, indica o uso pela manhã e à tarde de xarope. E partindo dessa premissa, indica duas receitas em latim: uma para os senhores e outra para pessoas comuns. Somente após o consumo desse xarope, poderia realizar a purga dos humores bile amarela e fleuma. Ainda em relação aos preceitos prático-terapêuticos, recomenda a retirada do excesso do humor sangue por meio de sangria ${ }^{11}$ da veia que se chama mediana (RPP, art. V, parte II, cap. V). 
Quanto à segunda coisa não natural, no Regimen em estudo, não é recomendado exercícios em tempos de epidemia. Assim, o autor indica-se evitar atividades que exigem grande esforço como caçar a pé, saltar, lutar, entre outras, pois por meio da respiração enviaria muito ar corrompido ao coração e consequentemente alteraria o calor inato, localizado neste órgão, e responsável pela realização das ações vitais no corpo humano (RPP, art. V, parte II, cap. II).

Em relação à quarta coisa não natural, o sono, recomenda-se dormir escolhendo a habitação nas condições indicadas em relação ao ar que se for corrompido por excesso de calor e adotando as seguintes medidas com o objetivo de esfriar o ambiente e auxiliar o sono: por roupa de cama molhada em água fria estendida na varanda e colocar uma bacia com água no meio da habitação. Por outro lado, em tempos de epidemia, quando o ar está putrificado e com odor fétido, recomenda antes de dormir colocar travesseiro com rosas secas na cabeceira da cama para auxiliar na qualidade do sono do indivíduo (RPP, art. V, parte II, cap. IV).

As paixões ou acidentes da alma $^{12}$ são abordados no quinto artigo do Regimen. Esta sexta coisa não natural refere-se à influência das emoções na saúde do homem. Elas estão situadas no ponto de união entre o físico e o espiritual e seu estudo pertence a um duplo domínio: o da moral e o da Medicina. Assim, no pensamento médico medieval, tendo como arcabouço teórico os escritos hipocráticos e galênicos, as emoções eram concebidas como as inclinações que rompem o equilíbrio da vida psíquica podendo modificar ou alterar o corpo saudável gerando inclusive vários sintomas somáticos característicos das paixões como mudança na cor da pele, batimentos cardíacos acelerados, aquecimento, arrefecimentos, entre outros. Portanto, os acidentes da alma como a tristeza, a ira e a alegria eram considerados como campo de domínio médico (SOTRES, 1995: 276-277; PEÑA e GIRON, 2006: 173 - 176).

Assim, no regimento de epidemia em análise, Jacme d'Agramont considera que as emoções exercem modificações físicas no corpo principalmente em tempo de epidemia. Os acidentes da alma são classificados de acordo com os benefícios e malefícios que poderiam causar à saúde das pessoas. A alegria é considerada a paixão mais benéfica e com efeito proveitoso sobre o corpo. Por outro lado, a ira, a tristeza, o temor, a angústia, entre outros, exerciam influências negativas. Assim, observando que em tempos de enfermidades pestilentas, é comum acidentes da alma vistos como nocivos, é interessante observar que o autor aconselha evitar o medo e a imaginação de 
morrer em função da peste, pois estes gerariam desânimo e desespero que são considerados prejudiciais à manutenção da saúde. Em sua concepção, o importante é seguir as recomendações presentes em sua obra acerca da preservação da saúde eliminando ou evitando todas as coisas que poderiam causar a pestilência (RPP, art. V, parte II, cap. VI).

\section{Considerações finais}

O Regimento de preservação da pestilência foi dirigido aos senhores de Lérida, pois na concepção de Jacme d'Agramont, a elite da cidade deveria ser responsável por ações visando o bem comum. Nesta perspectiva, eles deviam considerar que os aspectos da vida urbana que se incluem hoje dentro da epígrafe de "saúde pública" eram beneficiadores para o povo. Assim, no contexto da epidemia no século XIV, pensar em medidas práticas acerca da saúde e da prevenção em relação à peste era do interesse tanto dos físicos como dos dirigentes da cidade.

Essa preocupação acerca da utilidade "comum e pública" dos preceitos presentes na obra é identificada ao longo do Regimen. Nota-se que muitos dos produtos prescritos estavam entre os mais caros do mercado e, portanto, eram adquiridos pela elite ou "senhores" como afirma o autor. No entanto, observa-se o constante cuidado por parte do físico catalão em sempre indicar outras opções de ingredientes que em sua concepção teriam o mesmo efeito, mas por serem mais baratos ou de fácil acesso no reino de Aragão, poderiam ser utilizados pelas pessoas comuns. Do mesmo modo, o autor ressalta a necessidade de prudência em relação às prescrições terapêuticas por ele indicadas que só poderiam ser ministradas por pessoas que exerciam ofícios médicos ou especialistas em medicamentos. Por outro lado, as medidas preventivas aconselhadas deveriam ser utilizadas por todos sem auxílio médico.

Por fim, no contexto da peste, físicos como Jacme d'Agramont a partir do arcabouço teórico fornecido pelas autoridades antigas e árabes e da experiência da prática médica elencaram uma série de medidas de cunho preventivo. Assim, estabeleceu como principal premissa, evitar elementos considerados responsáveis pela propagação da peste, como: lugares em que o ar e o ambiente estivessem corrompidos, o consumo de alimentos de regiões com a pestilência e o contato com pessoas enfermas. Do mesmo modo, indica ficar em locais com ar mais puro, cuidar da alimentação 
seguindo o princípio da moderação e da teoria dos contrários e demais preceitos dietéticos relacionados às coisas não naturais.

\section{Fontes}

AVERRÓIS. Coliget/El libro de las generalidades de la medicina. Madrid: Trotta, 2003.

AVICENA. The Canon of Medicine of Avicenna. Vol. I. New York: AMS Press, 1994.

HIPÓCRATES. Sobre la dieta. In: GARCIA GUAL, Carlos (Trad.). Tratados Hipocráticos. Madrid: Editorial Gredos, 1986, p. 19 - 116.

JACME D’AGRAMONT. Regiment de Preservació de Pestiléncia, 1348. In: VENY, Joan (Org.). Regiment de preservació de pestilência (1348) - Jacme d'Agramont. Barcelona: L Abadia de Montserrat, 2016.

\section{Referências}

ARRIZABALAGA, Jon. Facing the Black Death: perceptions and reactions of university medical practitioners. In: GARCIA-BALLESTER, Luís et al (Orgs.). Practical medicine from Salerno to the Black Death. Cambridge: Cambridge University Press, 1994, p. $237-288$.

GARCIA-BALLESTER, Luís. Un reto para el Galenismo: mejorar la salud. Artifex Factivus Sanitatis: saberes y ejercicio profesional de la medicina en la Europa pluricultural de la Edad Media. Granada, 2004, p. 533 - 553.

GARCÍA-BALLESTER, Luis. Nuevos valores y nuevas estrategias en medicina. In: La busque da de la salud: sanadores y enfermos en la España medieval. Barcelona: Península, 2001, p. $129-225$.

FAGUNDES, M. D. da Conceição. Saber médico e poder: as relações entre Arnaldo de Vilanova e a Coroa Aragonesa (século XIII-XIV). 2014. Tese (Doutorado em História) - Faculdade de História da UFG. Universidade Federal de Goiás, 2014. 
JACQUART, Danielle. A Escolástica Médica. In: GRMEK, Mirkod. (Org.). Historie de la pensée medical em Occident: Antiquité et Moyen Age. Paris: Seuil, 1995, p. $175-185$.

PEÑA, Carmen e GIRÓN, Fernando. La Prevención de La Enfermidad en La España Bajo Medieval. Granada: Editorial Universidad de Granada, 2006.

SANTOS, Dulce O. Amarante dos; FAGUNDES, Maria Dailza da C. Saúde e Dietética na Medicina Preventiva Medieval: O Regimento de Saúde de Pedro Hispano. (século XIII). In: Revista: História, Ciências, Saúde: Manguinhos. Rio de Janeiro: Fundação Oswaldo Cruz, Casa de Oswaldo Cruz, 2010, p. 333 - 342.

SOTRÉS, Pedro Gil. Les regimes de santé. In: GRMEK, Mirko D. (Org.). Histoire de la pensée medical en Occident: Antiquité et Moyen Age. Paris: Seuil, 1995, p. 257 281.

VENY, Joan. Introducció, transcripció i estudi lingüístic. Regiment de preservació de pestilência (1348) - Jacme d'Agramont. Barcelona: L Abadia de Montserrat, 2016.

\section{Notas}

\footnotetext{
${ }^{1}$ Este artigo é parte dos resultados obtidos com os projetos de pesquisa que venho desenvolvendo na Universidade Estadual de Goiás, tais como "Saúde, enfermidades e práticas terapêuticas em fontes medievais (séculos XII - XV)" e "O ensino médico na Universidade de Montpellier no medievo".

2 Ao longo do texto adotamos a sigla RPP para identificar a obra Regimento de Preservação da Pestilência.

${ }^{3}$ Em seu Regimen, Jacme d'Agramont apresenta no último artigo a peste moral compreendida como mudança contra natura nos sentimentos e pensamentos das pessoas gerando inimizades, rancor, guerras, roubos, mortes e destruição dos lugares.

${ }^{4}$ Montpellier, cidade localizada ao sul do reino francês, mesmo mantendo sua independência política, pertencia à Coroa de Aragão desde o início do século XIII. Em 1204, com o casamento de Maria (1180 1213), filha de Guilherme VIII de Montpellier, com Pedro I (1178 - 1213), rei de Aragão e conde de Barcelona, os descendentes desse matrimônio ocuparam o senhorio de Montpellier até ser transmitido para o rei da França, que o comprou em 1348.

5 A dietética refere-se ao ramo da parte prática da medicina que se dedica aos cuidados que devem ser tomados aos corpos saudáveis para manter-se a saúde. O conceito, além de englobar a dieta alimentar, envolve as demais coisas não naturais: o ar e o meio ambiente; o exercício e o repouso; a retenção e a expulsão; o sono e a vigília e as paixões da alma.

${ }^{6}$ Com base na premissa de que o exercício da medicina pressupunha o conhecimento em relação aos astros, na Idade Média, os físicos e boticários afirmavam que medidas terapêuticas como a sangria e determinadas plantas medicinais só deveriam ser administradas e prescritas ao enfermo no auxílio do tratamento de certa enfermidade de acordo com determinada fase da lua e a posições dos planetas.

7 A enfermidade Fogo de Santo Antônio é conhecida atualmente como ergotismo e considerada uma intoxicação causada pelo consumo de cereais contaminados com o esporão de centeio.

${ }^{8} \mathrm{Na}$ farmacologia medieval, os medicamentos eram elaborados em forma de pó, decocção (cozimento), infusões, unguentos (medicamento composto, para uso externo, de consistência pastosa, feito à base de
} 
ingredientes de origem vegetal e animal), eletuários (medicamento composto, confeccionado a partir de pó extraído de vegetais que deveriam ser misturados com mel ou açúcar), entre outros.

Acerca da denominação mitridato, Jacme d'Agramont afirma que é originário do nome de Mitrídates VI, rei do Ponto, situado ao norte da Anatólia. Consta que durante muitos anos, esse monarca do século I a.C., tomou diversos venenos, tornando-se imune a qualquer tipo de tóxicos. Assim, o fármaco mitridato, recebe esse nome por ser considerado um antídoto eficaz contra todos os tipos de venenos.

${ }^{10}$ Nos tratados farmacológicos, identificam-se quatro graus das qualidades em comparação com a compleição do paciente. Por exemplo, se um ingrediente é considerado frio e úmido em primeiro grau, significa que é menos frio e úmido que a compleição humana; em segundo grau, significa que é igual; em terceiro grau, significa que é mais frio e úmido; em quarto grau, é extremamente mais frio e úmido que a compleição.

${ }^{11}$ Procedimento terapêutico para eliminar o excesso de sangue por meio do uso, por exemplo, de flebotomia e ventosa.

${ }^{12}$ As sensações ou emoções recebem diferentes títulos nos textos médicos medievais. Na tradição filosófica, os elementos integrantes da vida emocional são denominados paixões da alma, mas, nas fontes médicas, predomina o título acidentes da alma. 